\title{
O IDOSO NO MUNDO DO TRABALHO: CONFIGURAÇÕES ATUAIS*
}

Cláudia Maria da Silva Sá1, Norma Valéria Dantas de Oliveira Souza² ${ }^{2}$ Célia Pereira Caldas³, Marcia Tereza Luz Lisboa ${ }^{4}$, Kelly Fernanda Assis Tavares ${ }^{5}$

RESUMO: Pesquisa bibliográfica, de natureza qualitativa e descritiva, cujo objeto é o idoso no mundo do trabalho. O objetivo foi analisar os impactos psicossociais para o idoso diante de sua manutenção ou reinserção no mundo do trabalho. A busca bibliográfica deu-se de maio a agosto de 2010, nas bases de dados LILACS, SciELO, BDENF e MEDLINE. Foram encontradas nove produções científicas. A discussão das informações estruturou-se nas categorias $A$ relação entre o mundo do trabalho e a pessoa idosa e $A$ situação psicossocial do idoso. O fenômeno da manutenção ou reinserção do idoso no mundo do trabalho tende a se incrementar e, portanto, necessita-se de um replanejamento das políticas públicas dirigidas a este fenômeno. Verificou-se que tal temática deve ser investigada em suas múltiplas dimensões e que um novo olhar para a organização e as condições de trabalho é premente, a fim de garantir saúde e segurança ao trabalhador idoso. PALAVRAS-CHAVE: Idoso; Trabalho; Saúde.

\section{THE ELDERLY IN THE WORLD OF WORK: CURRENT CONFIGURATIONS}

ABSTRACT: This bibliographic research, of qualitative and descriptive character, aimed to study the elderly in the world of work. The objective was to analyze the psychosocial impacts on the elderly caused by their remaining or re-entering the workforce. The bibliographic search was undertaken between May and August 2010, via the databases LILACS, SciELO, BDENF and MEDLINE. Nine research articles were found. Discussion of the information was structured around the categories The relationship between the world of work and the elderly person and The psychosocial situation of the Elderly. The phenomenon of elderly people remaining in or re-entering the workforce is tending to increase and, therefore, a re-planning of public policies regarding the phenomenon is necessary. It was ascertained that this thematic must be investigated in its many dimensions and that a fresh look at organization and conditions of work is urgently needed, so as to guarantee health and safety to the elderly worker. KEYWORDS: Elderly; Work; Health.

\section{EL ANCIANO EN EL MUNDO DEL TRABAJO: CONFIGURACIONES ACTUALES}

RESUMEN: Investigación bibliográfica, de naturaleza cualitativa y descriptiva, cuyo foco es el anciano en el mundo del trabajo. El objetivo fue analizar los impactos psicosociales para el anciano delante de su manutención o reinserción en el mundo del trabajo. La búsqueda bibliográfica ocurrió de mayo a agosto de 2010, en las bases de datos LILACS, SciELO, BDENF y MEDLINE. Fueron encontradas nueve producciones científicas. La discusión de las informaciones se ha estruturado en las categorías La relación entre el mundo del trabajo y el anciano y La situación psicosocial del anciano. El fenómeno de la manutención o reinserción del anciano en el mundo del trabalho tiene la tendencia de se incrementar y, por lo tanto, es necesario un nuevo planeamiento de las políticas públicas asociadas a este fenómeno. Se verificó que esta temática debe ser investigada en sus múltiplas dimensiones y que una nueva mirada para la organización y las condiciones de trabajo es primordial para garantizar salud y seguridad al trabajador anciano. PALABRAS-CLAVE: Anciano; Trabajo; Salud.

\footnotetext{
*Trabalho apresentado na disciplina eletiva "O cuidado da saúde do adulto e do idoso" do Programa de Pós-Graduação - Mestrado da Faculdade de Enfermagem da Universidade do Estado do Rio de Janeiro - FE UERJ.

${ }^{1}$ Enfermeira Hospital Universitário Pedro Ernesto. Mestre em Enfermagem

${ }^{2}$ Enfermeira. Doutora em Enfermagem. Professora da Graduação e do Programa de Pós-Graduação da FE UERJ. Procientista da UERJ. ${ }^{3}$ Enfermeira. Pós-doutora em Gerontologia. Membro do Conselho Estadual de Defesa dos Direitos da Pessoa Idosa. Vice-Diretora da Universidade Aberta da Terceira Idade - UERJ.

${ }^{4}$ Enfermeira. Doutora em Enfermagem. Membro da Diretoria Colegiada do Núcleo de Pesquisa em Enfermagem e Saúde do Trabalhador e do Núcleo de Pesquisa Fundamentos do Cuidado de Enfermagem da Escola de Enfermagem Anna Nery - EEAN UFRJ.

${ }^{5}$ Acadêmica de Enfermagem FE UERJ. Bolsista de Iniciação Científica 2009-2010 pela UERJ.
} 


\section{INTRODUÇÃO}

O objeto desse estudo tratou do idoso e do mundo do trabalho. O interesse pela temática emergiu a partir de discussões elaboradas na disciplina eletiva do Mestrado "O cuidado à saúde do adulto e do idoso", do Programa de Pós-Graduação da Faculdade de Enfermagem da Universidade do Estado do Rio de Janeiro (FE - UERJ). O objetivo foi analisar os impactos psicossociais para o idoso diante de sua manutenção ou reinserção no mundo do trabalho.

Através de uma visão mais aprofundada sobre algumas temáticas, como o mundo do trabalho, o trabalhador e sua subjetividade, as repercussões do trabalho na saúde do trabalhador, aumento da expectativa de vida da população brasileira, reconfiguração da organização do trabalho e globalização, surgiram vários questionamentos. Porém, destacaram-se, por serem mais inquietantes, tornando-se a problemática do presente estudo, os impactos psicossociais na vida do idoso diante de sua manutenção ou reinserção no mundo do trabalho.

Alguns estudos apontam para a participação cada vez maior do idoso no mundo do trabalho. Esse fato envolve uma série de razões que vão da necessidade do idoso de se manter produtivo e valorizado no meio social, passando pela sua carência econômica, isto é, a necessidade de assegurar um padrão de consumo aceitável e comparável aos parâmetros vividos por ele em anos anteriores, ou passando por ser uma estratégia para vencer a solidão e o isolamento impostos por uma sociedade que segrega os idosos ${ }^{(1-4)}$. A melhor condição de saúde, especialmente a preservação da autonomia e da mobilidade física, também tem sido um importante fator para a inserção e permanência no mundo do trabalho de pessoas com idades mais avançadas, a exemplo do que ocorre com os demais trabalhadores adultos ${ }^{(5)}$.

Existe uma interação permanente entre o trabalhador e seu ambiente de trabalho. Nesta interação, o ambiente do trabalho pode agir positiva ou negativamente na saúde do trabalhador, de sorte que seu bem-estar físico e mental influenciará a sua produtividade. Quando o trabalho está adaptado ao trabalhador, sua ação sobre este é potencializadora ou asseguradora de saúde. Mas, dependendo da organização do processo laboral, o trabalho poderá representar risco à saúde e ser causa de doenças profissionais e/ou agravar um estado de saúde deficiente, de origem extraprofissional ${ }^{(6)}$.
A definição de prioridades para as políticas públicas, o planejamento e implementação das ações em Saúde do Trabalhador estão diretamente relacionados a informações sobre a real situação de saúde dos trabalhadores. A escassez e inconsistência das informações dificultam essas ações e privam a sociedade de instrumentos relevantes para a melhoria das condições de vida e trabalho ${ }^{(7)}$. Esta situação se agrava quando focada no trabalhador idoso, uma vez que o fato de pessoas em faixa etária mais elevada se manterem no mundo do trabalho caracteriza um fenômeno recente e, por isso, tem sido pouco ou nada investigado e/ou priorizado pelos planejadores e gestores de políticas públicas.

\section{METODOLOGIA}

Este estudo caracterizou-se como bibliográfico, de natureza qualitativa e descritiva. A busca ocorreu no site da Biblioteca Virtual em Saúde, nas bases de dados LILACS, SciELO, BDENF e MEDLINE, com os descritores no formulário avançado identificados como "idoso", "trabalho" e "saúde". Optou-se pela busca de produções científicas em português, inglês e espanhol, sem limitação da data de publicação, com exceção da MEDLINE; para esta base de dados, buscaram-se as publicações de 1997 a 2010, por serem publicações mais recentes, não tendo sido encontrada produção relacionada a tais descritores. As consultas foram realizadas de maio a agosto do ano de 2010.

Na base de dados LILACS, no campo "palavras", encontraram-se 268 produções. No entanto, apenas 09 dessas estavam diretamente relacionadas ao idoso e o ao mundo do trabalho. Na base de dados SciELO, utilizando-se os mesmos descritores, no campo "todos os índices", foram encontradas 55 produções. Todavia, dessas, somente uma, indicada em uma busca mais refinada, tratava do objeto de estudo. Na BDENF, de 55 produções relativas ao campo "palavras", apenas duas eram relacionadas ao objeto, uma datada de 1.983 , que não foi incluída no estudo por ser considerada muito antiga, e outra já citada nas bases LILACS e SciELO.

\section{RESULTADOS}

Das 09 produções encontradas na base de dados LILACS, foram utilizadas apenas três delas, por estarem relacionadas ao objeto e por se adequarem aos critérios de inclusão do estudo (idioma e data de publicação). Vale destacar que outras referências também foram utilizadas na discussão com o fito de 
atingir os objetivos do estudo. As produções científicas analisadas e discutidas foram: Trabalho, qualidade de vida e envelhecimento ${ }^{(4)}$, de Moreira; Saúde, trabalho e envelhecimento no Brasil $^{(5)}$, de Giatti, Barreto; e $O$ significado do processo de envelhecimento no mercado de trabalho e suas implicações na saúde dos(as) trabalhadores(as) $)^{(8)}$, de Bretãs.

O estudo referente ao texto Trabalho, qualidade de vida e envelhecimento, caracterizou-se como uma dissertação de mestrado, trazendo como principais pontos de reflexão as seguintes proposições: o trabalho como fonte de aumento da qualidade de vida, proporcionando ao idoso a atividade física e intelectual, e o trabalho como agravante da qualidade de vida, quando as condições laborais e a organização do trabalho não consideram as especificidades da pessoa idosa. Este estudo referiu também que o trabalho pode ser um elemento importante para gerar a qualidade de vida, desde que seja associado ao $\operatorname{prazer}^{(4)}$.

A produção que teve como título Saúde, trabalho e envelhecimento no Brasil tratou da inserção dos idosos no mercado de trabalho, segundo atividade produtiva desenvolvida, correlacionando fatores sociodemográficos e de saúde com algumas situações laborais desse segmento da população. $\mathrm{O}$ estudo teve como sujeitos 2.886 idosos do sexo masculino, com 65 anos ou mais de idade. Alguns dos principais resultados apreendidos neste estudo foram: os idosos que se mantinham no mercado de trabalho eram os mais jovens (próximos da faixa etária dos 65-70 anos); tinham maior escolaridade e maior renda domiciliar per capita; apresentavam menor frequência de doenças crônicas; e menor dificuldade para realização das atividades da vida diária. Estes idosos não apresentavam diferenças com relação ao uso de serviços de saúde se comparados à faixa etária de pessoas adultas. A pesquisa concluiu que a permanência na vida ativa pode possuir como forte determinante a capacidade física, quando associada ao trabalho e a melhores indicadores de autonomia e mobilidade física, ainda que se trate de idade mais avançada ou outros fatores sociodemográficos ${ }^{(5)}$.

Na produção científica intitulada $O$ significado do processo de envelhecimento no mercado de trabalho e suas implicações na saúde dos(as) trabalhadores(as) verificou-se uma discussão sobre o significado do processo do envelhecimento e seus reflexos no mercado de trabalho, além das implicações na saúde do indivíduo e do coletivo social. Constatou-se também que o estudo faz uma análise sobre as transformações no mundo do trabalho no modelo produtivo capitalista e suas tecnologias, focando nas questões de desemprego estrutural e nas consequências para a saúde e para o envelhecimento dos indivíduos ${ }^{(8)}$.

\section{ANÁLISE E DISCUSSÃO}

Após a análise das referências selecionadas, decidiu-se desenvolver a discussão dos dados a partir de duas categorias: "A relação entre o mundo do trabalho e a pessoa idosa" e "A situação psicossocial do trabalhador idoso".

\section{A relação entre o mundo do trabalho e a pessoa idosa}

A pessoa idosa é aquela com idade igual ou superior a 60 anos, tomando-se por base a definição do artigo $1^{\circ}$ do Estatuto do Idoso, Lei n. 10.741/2003 ${ }^{(9)}$.

Ao longo da história recente, formou-se no senso comum a concepção de que o trabalho, por exercer exploração exacerbada da força física do trabalhador nas indústrias, seria insustentável para o idoso. Assim, o idoso foi colocado à margem do mundo do trabalho, pois, não sendo mão-de-obra eficazmente produtiva, estaria condenado a ser um fardo para a sociedade. Mesmo com o conjunto de normas elaboradas pelo Estado, regulando as relações empregatícias, a fim de estabelecer limites a todo tipo de excesso exigido por parte do empregador, a mentalidade de que o idoso seria uma mão-de-obra ultrapassada não se desfez ${ }^{(3)}$.

A pessoa idosa, portanto, pela dificuldade de inserção no mercado de trabalho, constitui uma parcela da população vulnerável à pobreza, passando a depender de outras fontes de renda, principalmente da aposentadoria ${ }^{(10)}$. Contraditoriamente, um número significativo de idosos, em muitos países, representa um recurso vital para a sobrevivência econômica de várias famílias. É por isso que cada vez mais idosos continuam inseridos no mundo do trabalho formal, e também no informal ${ }^{(11)}$.

Para expressar o processo de avanço do envelhecimento como uma experiência positiva da humanidade, a Organização Mundial de Saúde (OMS) adotou a expressão "envelhecimento ativo". Esta expressão é definida como sendo o processo de otimização das oportunidades de saúde, participação e segurança, com o objetivo de melhorar a qualidade de vida das pessoas, à medida que ficam mais velhas. Contudo, a busca de uma boa qualidade de vida para os idosos requer também mudanças na cultura sobre a visão da velhice, 
que ainda compreende o processo de envelhecimento como uma fase de doença e fragilidade ${ }^{(12)}$.

O envelhecimento ativo visa a aumentar a qualidade e a expectativa de vida para todas as pessoas no processo de envelhecer, incluindo as que são frágeis, fisicamente incapacitadas e que requerem cuidados ${ }^{(11)}$.

Sendo o trabalho uma forma de manter o idoso em atividade física ou intelectual, ele pode ser também um bom meio de alcance da qualidade de vida na terceira idade. No entanto, três considerações devem necessariamente ser feitas. A primeira é que não é qualquer trabalho que pode ser sinônimo de bem-estar e aumento da qualidade de vida para as pessoas idosas. O exercício de atividades laborais deve envolver igualmente o sentimento de prazer, indo além do mero entendimento de que o indivíduo significa unicamente uma fonte financeira para outras pessoas. $\mathrm{O}$ segundo aspecto é que o trabalho, para muitos idosos, é condição central de suas vidas, devido a ter sido precoce sua inserção no mundo do trabalho, por conseguinte o trabalho continua sendo um importante referencial de suas vidas. O trabalho é uma maneira que eles têm de sentir-se "úteis" para a sua família e para a sociedade após a aposentadoria. E a terceira consideração é que o trabalho não deve ser a única alternativa para se ter qualidade de vida, embora algumas pessoas tenham tido suas vidas centradas exclusivamente no trabalho e não se permitiram viver outros prazeres ${ }^{(4)}$.

Em consonância com o cenário mundial de aumento da proporção de pessoas com mais de 60 anos, o Brasil apresenta-se com uma significativa população jovem; no entanto, a faixa etária com maior crescimento é a dos idosos. Em 1995, a população de idosos era de 11 milhões, enquanto se estima que, em 2025, o Brasil já terá 32 milhões de idosos ${ }^{(13)}$.

A aposentadoria oficial é a principal fonte de sobrevivência das pessoas idosas, ainda que ela não seja suficiente para atender suas necessidades básicas. Devido às graves distorções na distribuição de renda no país, muitos idosos vivem em extrema pobreza, enquanto outros, para não ver reduzido o seu padrão de vida, são forçados a prolongar sua permanência no mundo do trabalho, ou conforme o caso, obrigados a retornar às atividades laborais para garantir condições mínimas de sobrevivência ${ }^{(2)}$.

Em 2003, a participação das pessoas com mais de 60 anos na População Economicamente Ativa era de 21,9\% na região metropolitana de São Paulo. De 357 mil pessoas idosas, 328 mil estavam ocupadas e 31 mil, desempregadas. A maioria dos idosos ocupados estava mais concentrada no setor de serviços $(52,8 \%)$ e no comércio (22,3\%); já na indústria, a participação era de $11,9 \%$. Dos ocupados com mais de 60 anos, 43,9\% eram autônomos; 31,4\%, assalariados; 9,8\%, empregados domésticos e 9,7\%, empregadores ${ }^{(13)}$.

Uma situação está paradoxalmente presente no mundo do trabalho do idoso: o aumento da experiência profissional em contraposição com a diminuição da sua capacidade física. A diminuição da capacidade laboral não se apresenta como decorrência lógica do avanço da idade, uma vez que, dependendo da função exercida, ao contrário, a idade avançada representa, pela experiência do idoso, um aumento da qualidade do serviço por ele prestado. Vale enfatizar que existem atividades laborais nas quais a experiência adquirida, tanto na vida profissional quanto na vida particular, representa um adicional à capacidade produtiva do trabalhador ${ }^{(3)}$.

A sociedade capitalista estereotipa os seres humanos à medida que estes envelhecem, fazendo valer a máxima de que envelhecimento se coloca inversamente proporcional à produtividade do indivíduo. Em realidade, a produtividade está diretamente relacionada com a motivação individual do trabalhador para a realização do trabalho e varia em grau de intensidade conforme a natureza da atividade desenvolvida pelo trabalhador ao longo de sua vida laboral ${ }^{(8)}$.

A industrialização, a adoção de novas tecnologias e a mobilidade do mercado de trabalho são fatores que ameaçam muito o trabalho tradicional dos idosos, especialmente nas áreas rurais. Nos países em desenvolvimento, onde o índice de desemprego é alto, há uma tendência a reduzir o número de trabalhadores mais velhos como meio de criar emprego para os mais jovens ${ }^{(11)}$.

De acordo com relatório da OMS, durante séculos, a idade média do trabalhador não se alterou de modo significativo, não tendo sido necessário adaptar o posto de trabalho para atender as necessidades dos trabalhadores de mais idade. No entanto, como a idade média do trabalhador continuará aumentando, a interação entre o trabalhador que está envelhecendo e o posto e o ambiente de trabalho deverá ser cada vez mais considerada pelas sociedades ${ }^{(14)}$. Assim, estudos da própria OMS recomendam que os profissionais que lidam com os trabalhadores com mais idade deverão destinar atenção especial a vários aspectos das condições de trabalho, como a organização do trabalho, os fatores psicológicos, ergonômicos, físicos e químicos, a fim de proporcionar maior qualidade de vida ao trabalhador idoso ${ }^{(14)}$. 


\section{A situação psicossocial do trabalhado idoso}

O envelhecimento populacional promove transformações profundas na sociedade, na estrutura familiar e no mercado de trabalho, trazendo a necessidade de criação de políticas públicas, em especial nas áreas de saúde e seguridade social. Idosos com boas condições de saúde, com preservação de autonomia física e mental, mantêm boas perspectivas de vida e podem assumir papeis relevantes na sociedade ${ }^{(5)}$.

Em todo o mundo, se os trabalhadores tivessem boas oportunidades de trabalho, com remuneração adequada, ambientes laborais dignos e protegidos contra riscos, iriam chegar à velhice ainda capazes de participar da força de trabalho. Essa realidade traria benefícios para toda a sociedade. Mundialmente, há um aumento do reconhecimento da necessidade de apoiar a participação ativa e produtiva que os idosos podem ter, seja no trabalho formal, no informal, nas atividades não remuneradas domiciliares ou em ocupações voluntárias ${ }^{(11)}$.

No entanto, as organizações ainda não estão completamente adaptadas para lidar com o trabalhador idoso. Tampouco a sociedade está conscientizada a respeito desta questão ${ }^{(14)}$. Há muito que se pesquisar sobre o trabalho, sobre as pessoas idosas e sobre a adaptabilidade do trabalho a estas pessoas. Trata-se de uma nova demanda para a produção do conhecimento, em várias áreas ${ }^{(1)}$.

No que se refere à desejada igualdade entre o trabalhador jovem e o trabalhador idoso no mundo do trabalho, ela somente se verificará se o empregador atender a determinadas circunstâncias especiais que respeitem as condições físicas, intelectuais e psíquicas do trabalhador idoso. Este deve ser protegido de trabalhos penosos, insalubres, com jornadas excessivas, ou exercidos em ambientes geradores de alta carga de pressão psicológica, pois estes poderão ser considerados atos contrários aos direitos ao trabalho e à igualdade do idoso ${ }^{(3)}$.

Envelhecer é um processo de modificações biofisiológicas e psicossociais complexas, tanto para a pessoa idosa como para a sociedade. A velhice é uma etapa da vida do ser humano em que o comportamento está mais propenso a frustrações, desajustes e conflitos diante de situações novas ${ }^{(1)}$.

No contexto subjetivo da vida do idoso, verificam-se sentimentos e situações que podem produzir dificuldades para a sua integração ao trabalho, tais como solidão, abandono, rejeição, marginalização, inutilidade, angústia existencial, medo, desespero, sensação de fracasso, empobrecimento gradativo, conflito de gerações e incapacidade ou falta de energia para mudar e massificação ${ }^{(1)}$.

Todo e qualquer trabalho é potencialmente capaz de gerar prazer ou sofrimento, ainda que, ao longo da história, tenha se apresentado como gerador de sofrimento mais do que como fonte de prazer, em decorrência, principalmente, de suas formas de organização e condições de realização ${ }^{(15)}$.

$\mathrm{Na}$ medida em que a organização do trabalho é rígida, mais acentuada se torna a divisão do trabalho e menor o conteúdo significativo e as possibilidades de mudá-lo ${ }^{(16)}$, abortando a margem de criatividade do trabalhador. Todas essas questões levam ao aumento do sofrimento psíquico.

A organização do trabalho nas instituições que lidam com trabalhadores idosos necessita ser mais flexível nos seguintes aspectos: ritmo de trabalho, que deve ser estabelecido pelo próprio trabalhador e não pela máquina ou exigências do grupo; horas de trabalho e variedade nas exigências físicas e cognitivas $^{(16)}$. Já com relação aos fatores psicológicos, cabe destacar aqueles ligados às funções do trabalho, ao futuro profissional e à participação e controle do próprio trabalhador idoso ${ }^{(14)}$ :

\begin{abstract}
Incertezas a respeito do papel do trabalhador de idade no local de trabalho incidem no desempenho e na confiança em si mesmo. As preocupações com relação ao futuro profissional (aposentadoria, promoção, desemprego em época de recessão) afetam o desempenho no trabalho e a saúde do trabalhador. O trabalhador de idade tende a ser mais leal às metas da organização $0^{(14: 15)}$.
\end{abstract}

Considerando as variáveis do mundo do trabalho, a subjetividade do trabalhador e a realidade do idoso, pode-se inferir que os profissionais que lidam com saúde e segurança no trabalho, os empregadores, os próprios trabalhadores idosos, os governos e a sociedade precisam ser mobilizados a implementar ações e avaliá-las no sentido de ter maior compreensão sobre quais repercussões são esperadas diante da permanência ou reinserção do idoso no mundo do trabalho.

\section{CONSIDERAÇÕES FINAIS}

Pela escassez de estudos relacionados à realidade do trabalhador idoso, verificou-se que essa é uma temática que precisa ser investigada em suas múltiplas dimensões, principalmente, porque a expectativa de 
vida cresce a cada dia e as tecnologias podem ser postas em favor de uma melhor qualidade de vida. Contraditoriamente, a globalização e o capitalismo neoliberal vêm empobrecendo a maioria das pessoas, além de produzir o desemprego estrutural, fenômenos que não só pressionam a manutenção de todos os trabalhadores no mercado de trabalho, como também os impele à busca de formas adicionais de renda, como é o caso dos idosos.

Constata-se que, com base nos estudos analisados, o fenômeno da manutenção ou reinserção do idoso no mundo do trabalho tende a se incrementar, portanto, faz-se mister um replanejamento das políticas públicas com esse foco. Da mesma forma, necessita-se de um novo olhar para a organização laboral e para as condições de trabalho, a fim de garantir saúde e segurança ao trabalhador idoso.

O trabalho, por influenciar positiva ou negativamente o indivíduo, necessita ser avaliado e adaptado às características do trabalhador para que seja, predominantemente, fonte de prazer e saúde. Tal premissa torna-se singular no caso do trabalhador idoso, que está em uma fase de múltiplas alterações e adaptações, as quais necessitam ser compreendidas e acompanhadas pelo mundo dinâmico do trabalho, quando não pelo próprio indivíduo.

Considera-se que o objetivo deste estudo foi atingido, no entanto, a problemática abordada sugere que ainda há muito para ser pesquisado. Durante a sua elaboração, perguntas sobre onde e de que forma os idosos estão sendo inseridos no mundo do trabalho ganharam força. Por outro lado, cabe também perguntar se a permanência no mundo do trabalho é um fenômeno que tende para o prazer ou para o sofrimento do trabalhador idoso? E ainda um último ponto é aquele que remete às eventuais mudanças que deverão ser elaboradas na organização e no processo de trabalho para assegurar a saúde do trabalhador idoso.

Todas essas questões, transformadas em objetos de estudo e respondidas, poderão, posteriormente, reverter em ganhos para a Saúde do Trabalhador, para a Gerontologia, e, particularmente, para a qualidade de vida do idoso que trabalha.

\section{REFERÊNCIAS}

1. Silva RDM. O trabalho da pessoa idosa e a sua relação com o sofrimento e o prazer: um estudo qualitativo realizado numa empresa privada [dissertação]. Florianópolis (SC): Universidade Federal de Santa Catarina; 1999.
2. Fernandez JC, Menezes WF. O idoso no mercado de trabalho: uma análise a partir da região metropolitana de Salvador. Rev Econ Nordeste. [Internet] 2001; 32(1) [acesso em 04 jan 2010]. Disponível: http://www. portaldoenvelhecimento.org.br/artigos/idoso_salvador. pdf.

3. Araújo AA. O direito ao trabalho e à profissionalização do idoso. [Internet]. [acesso em12 dez 2009]. Disponível: http://www.prt21.gov.br/estag/alyane.pdf

4. Moreira MMS. Trabalho, qualidade de vida e envelhecimento [dissertação]. Rio de Janeiro (RJ): Fundação Oswaldo Cruz; 2000.

5. Giatti L, Barreto SM. Saúde, trabalho e envelhecimento no Brasil. Cad Saude Publica. [Internet] 2003;19(3) [acesso em 07 maio 2010]. Disponível: http://www. scielosp.org/pdf/csp/v19n3/15879.pdf.

6. Marín MJC. El trabajo y la salud. In: Moreno, A. S. et al. Enfermeria comunitaria: concepto de salud y factores. Madrid: Mc Graw-hill/ Interamericana; 2000.

7. Ministério da Saúde (BR). Política Nacional de Segurança e Saúde do Trabalhador: 2004. [acesso em 16 jun 2010] Disponível:http://portal.saude.gov.br/portal/ arquivos/pdf/insumos_portaria_interministerial_800. pdf

8. Brêtas ACP. O significado do processo de envelhecimento no mercado de trabalho e suas implicações na saúde dos(as) trabalhadores(as). Texto \& Contexto Enferm. 2001;10(2):34-51.

9. Senado Federal (BR). Comissão Diretora.[Internet] Brasília: DF; [acesso em 18 dez 2009]. Estatuto do idoso. Anexo ao parecer n. 1301, de 2003. Disponível: http:// www.crde-unati.uerj.br/pdf/estatuto.pdf.

10. Marin MJ, Cecílio LCO, Rodrigues LCR, Ricci FA, Druzian S. Diagnóstico de enfermagem de idosas carentes de um programa de saúde da família (PSF). Esc Anna Nery Rev Enferm. 2008;12(2):278-84.

11. World Health Organization (WHO). Envelhecimento ativo: uma política de saúde. Trad. de Suzana Gontijo. 2005. [acesso em 04 jan 2010]. Disponível: http://bvsms. saude.gov.br/bvs/publicacoes/envelhecimento_ativo. pdf.

12. Nicolazi M, Silva J, Coelho L, Cascaes A, Büchele F. Qualidade de vida na terceira idade: um estudo na atenção primária em saúde. Cogitare Enferm. 2009;14(3):428-34. 
13. No batente: idosos mantêm lugar no mercado de trabalho. Folha de S. Paulo. [Internet] São Paulo; 2004 [acesso em 18 fev 2009]. Disponível: http://wwwl.folha. uol.com.br/fsp/dinheiro/fi2709200410.htm.

14. Salomão JC. Conseqüências do envelhecimento da população trabalhadora e sua relação com o comportamento organizacional. In: Anais do XII Encontro de Estudos Populacionais da ABEP; [Internet]. 2000 [acesso em 10 abr 2009]. Disponível: http://www.abep.nepo.unicamp.br/ docs/anais/pdf/2000/Todos/idot5_3.pdf.

15. Lunardi Filho WD. Prazer e sofrimento no trabalho: contribuições à organização do processo de trabalho da enfermagem [dissertação]. Porto Alegre (RS): Universidade Federal do Rio Grande do Sul; 1995.

16. Dejours C. A loucura do trabalho: um estudo de psicopatologia do trabalho. São Paulo: Cortez-Oboré; 1992. 